Article

\title{
Effect of Biochar Application Depth on Crop Productivity Under Tropical Rainfed Conditions
}

\author{
Juana P. Moiwo ${ }^{1, * \mathbb{C}}$, Alusine Wahab ${ }^{1}$, Emmanuel Kangoma ${ }^{1}$, Mohamed M. Blango ${ }^{1}$, \\ Mohamed P. Ngegba ${ }^{2}$ (I) and Roland Suluku ${ }^{3}$ \\ 1 Department of Agriculture and Biosystems Engineering, School of Technology, Njala University, PMB, \\ Freetown 47235, Sierra Leone \\ 2 Department of Extension and Rural Sociology, School of Agriculture, Njala University, PMB, Freetown 47235 , \\ Sierra Leone \\ 3 Department of Animal Science, School of Agriculture, Njala University, PMB, Freetown 47235, Sierra Leone \\ * Correspondence: jupamo2001@yahoo.com; Tel.: +232-76542008
}

Received: 11 January 2019; Accepted: 26 February 2019; Published: 27 June 2019

Featured Application: Biochar is an exciting discovery in the search for a solution to the deteriorating environmental and climatic conditions in the age. When activated and applied, it has the potential to adsorb hold on both carbon and nutrients and remain fertile for a considerably long period of time. Unfortunately, farming in especially western Africa is still dominated by the slash-burn shifting cultivation. Here, a considerable amount of charcoal from a mix of biomass stock is left behind after burning and plowed into the soil during cultivation. This study targets this system of cultivation. It is the long journey to the transformation of the burning to charcoal to pyrolysis to biochar to enrichen the soil.

\begin{abstract}
Although inherently fertile, tropical soils rapidly degrade soon after cultivation. The period of time for which crops, mulch, compost, and manure provide nutrients and maintain mineral fertilizers in the soil is relatively short. Biochar, on the other hand, has the potential to maintain soil fertility and sequester carbon for hundreds or even thousands of years. This study determined the effect of biochar application depth on the productivity of NERICA-4 upland rice cultivar under tropical rainfed conditions. A fixed biochar-soil ratio of 1:20 (5\% biochar) was applied in three depths $-10 \mathrm{~cm}(\mathrm{TA}), 20 \mathrm{~cm}(\mathrm{~TB})$, and $30 \mathrm{~cm}$ (TC) with a non-biochar treatment (CK) as the control. The study showed that while crop productivity increased, root penetration depth decreased with increasing biochar application depth. Soil moisture was highest under TA (probably due to water logging in sunken-bed plots that formed after treatment) and lowest under TC (due to runoff over the raised-bed plots that formed too). Grain yield for the biochar treatments was $391.01-570.45 \mathrm{~kg} / \mathrm{ha}$ (average of $480.21 \mathrm{~kg} / \mathrm{ha}$ ), with the potential to reach $576.47-780.57 \mathrm{~kg} / \mathrm{ha}$ (average of $695.73 \mathrm{~kg} / \mathrm{ha}$ ) if contingent field conditions including pest damage and runoff can be prevented. By quantifying the effect of externalities on the field experiment, the study showed that biochar can enhance crop productivity. This was good for sustainable food production and for taking hungry Africa off the donor-driven food ration the nation barely survives on.
\end{abstract}

Keywords: biochar; tropical rainfed condition; crop productivity; root-zone soil; application depth

\section{Introduction}

Biochar is charcoal produced by burning biomass under controlled temperature and oxygen conditions, mainly for the purpose of soil amendment [1-4]. As a porous material with active functional groups, high $\mathrm{pH}$ and cation exchange capacity [5], biochar can serve as a natural pool of organic carbon 
and plant nutrient in the soil [6-8]. There is a widespread interest in biochar research because of its rediscovered potential to mitigate climate change, amend soils and increase crop productivity $[9,10]$. However, this potential is strongly influenced by biochar production (temperature, oxygen supply, etc.), application (rate, mode, time, soil type, etc.) and feedstock (plant, animal, domestic waste, etc.) conditions [11-15].

The highly fertile dark earths (the so-called terra preta) left behind centuries ago by the prehistoric Amerindians are characteristically rich in carbon [16-18]. The origin of the rich dark earths is traced to as far back as 1542 when Orellana first reported to the Spanish Court on the well-established networks of agricultural settlements along a tributary of the Amazon River $[19,20]$. Unlike the predominantly terra mulata (brown earths), which is the natural soil in the Amazon, terra preta dark earths is anthropogenic or anthropic creation of humans [20-22]. Typically, terra preta has three or more times total soil organic carbon and far more phosphorus, calcium and humus than the surrounding terra mulata brown soils. The Amazonian terra preta has remained highly fertile centuries after its formation.

In addition to the potential to sequester carbon, the porous structure, large surface area, and high particle charge of biochar [23] interact with the soil [24-26] that results in beneficial effects on the ecosystem [27]. Among the countless benefits of the use of biochar are enhanced plant growth [28], improved soil water-holding capacity [29], reduced crop diseases [30], limited bioavailability of heavy metals [31], reduced soil nitrogen oxide emission [32], and reduced leaching of nutrients and fertilizers [29]. Schmidt et al. [33] and Schmidt [34] have documented a more exhaustive list of the beneficial uses of biochar. Biochar is hailed as an all-win solution to global energy, food, and environmental challenges [11].

In the tropics where soil fertility is depleted soon after cultivation in the predominantly slash-burn shifting cultivation $[8,20,35]$, there is the need to switch to slash-char sedentary farming for sustainable crop production $[32,36]$. Slash-burn shifting cultivation destroys up to $97 \%$ of soil organic carbon as against less than $50 \%$ under slash-char farming, of which most is retained as highly stable organic carbon [16,24]. With an average residence time of over 1000 years [37], biochar can sustain crop productivity for as long as it remains active in the soil [38].

In a meta-analysis including 116 studies from 21 countries around the world, Liu et al. [39] noted that biochar increases crop productivity by $11 \%$ on average. In another meta-analysis including 371 independent studies, Biederman and Harpole [40] noted considerable variations in the degree of enhancement of crop yield components and soil properties. Biochar application rates below 30 tons/ha typically result in $30 \%$ more productivity of legume and $29 \%$ more of vegetable crops than of cereal crops such as corn $(8 \%)$ and rice $(7 \%)[38,40]$. Studies, including literature data analyses, also show that biochar application rates above 55 tons/ha can lead to reductions in crop productivity $[16,40]$.

The terra preta soil, which has so much reignited biochar research, occurs in varying depths and rates across the Amazon [20]. This forms the basis for investigation of the variations in soil/crop response to biochar application rates in terms of biochar-soil mixture, activation mode and/or application depth. In this study, a field experiment was conducted to determine the effect of biochar application depth on rice crop productivity under tropical rainfed conditions. The results of the study will add to the efforts in understanding the potential of biochar to sustainable crop production, improve soil properties and mitigate global climate change.

\section{Materials and Methods}

\subsection{Study Area}

This study was conducted at the experimental site at the Department of Agricultural Engineering, Njala University. The site is located at $012.07762^{\circ} \mathrm{W}, 08.10958^{\circ} \mathrm{N}$ and is $80 \mathrm{~m}+\mathrm{MSL}$ (above mean sea level); which is in Kori Chiefdom in the southern province of Sierra Leone (Figure 1). The study area has a typical tropical climate, with gravelly brown soil and shrub vegetation [32,41]. 
Here, there are two distinct seasons-the wet season (WS) and dry season (DS). The WS (May to Oct.) is characterized by cloudiness, heavy rains, and by low temperatures, solar radiation, photoperiod, and sunshine hours, but high humidity. In the DS (Nov. to Apr.), the climatic condition is the near-reverse of that of the WS. The unimodal average annual rainfall is $2526 \mathrm{~mm}$ and the temperature is $31^{\circ} \mathrm{C}$. While over $80 \%$ of the rain falls in the WS, solar radiation is highest in March $\left(604 \mathrm{MJ} / \mathrm{m}^{2} /\right.$ day).

The soils at the experimental site are typical Oxisols and Ultisols and therefore generally slightly acidic [42], but nonetheless good for rice cultivation. Biochar is reported to have $\mathrm{pH}$ range of 10-12 [43] and therefore suitable for application in such soils.

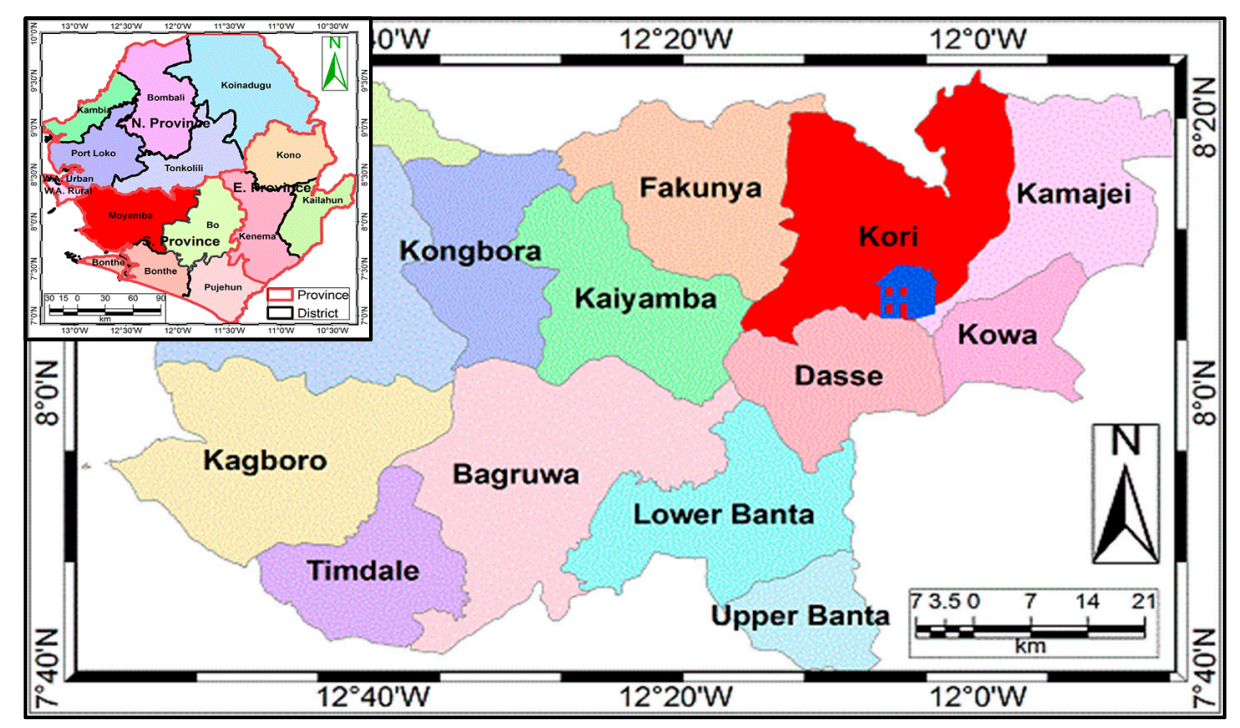

Figure 1. A map depicting Moyamba District (red) in the southern province of Sierra Leone (inset) and then an expanded map of the province (main plate) depicting Kori Chiefdom (red) and the location of the Njala University study area (blue house) in the chiefdom.

\subsection{Biochar Preparation}

The wood biomass used in the biochar production was a random collection in the bush nearby $(1-2 \mathrm{~km})$ the experimental site. The random wood mix was as much as possible similar to the normal conditions under which charcoal is unintentionally added to the soil under the conventional slash-burn shifting cultivation practiced in the region [35]. The dry wood biomass was fed into a locally-built Elsa Stove (retort kiln) of $55 \mathrm{~cm}$ in diameter and $90 \mathrm{~cm}$ in height and allowed to burn at $350-550{ }^{\circ} \mathrm{C}$ under low oxygen condition [32]. The pyrolyzed wood biomass (called biochar) was then collected, ground into fine dust and stored for later application in the field.

\subsection{Site Preparation}

The experimental site was cleared and leveled in July 2016 using simple farm tools including machete, hoe and shovel. A total of 24 plots (each $1.0 \mathrm{~m} \times 1.0 \mathrm{~m}$ with $0.5 \mathrm{~m}$ footpath) were constructed and separated out by bamboo canes to prevent flow of water, soil and nutrient across the plots (Figure 2). Also, a drainage was constructed around the entire field site to prevent runoff on to the plots. The dimension of the experimental field site was $12.5 \mathrm{~m} \times 5.0 \mathrm{~m}$ (length by width), with a total area of $62.5 \mathrm{~m}^{2}$. 


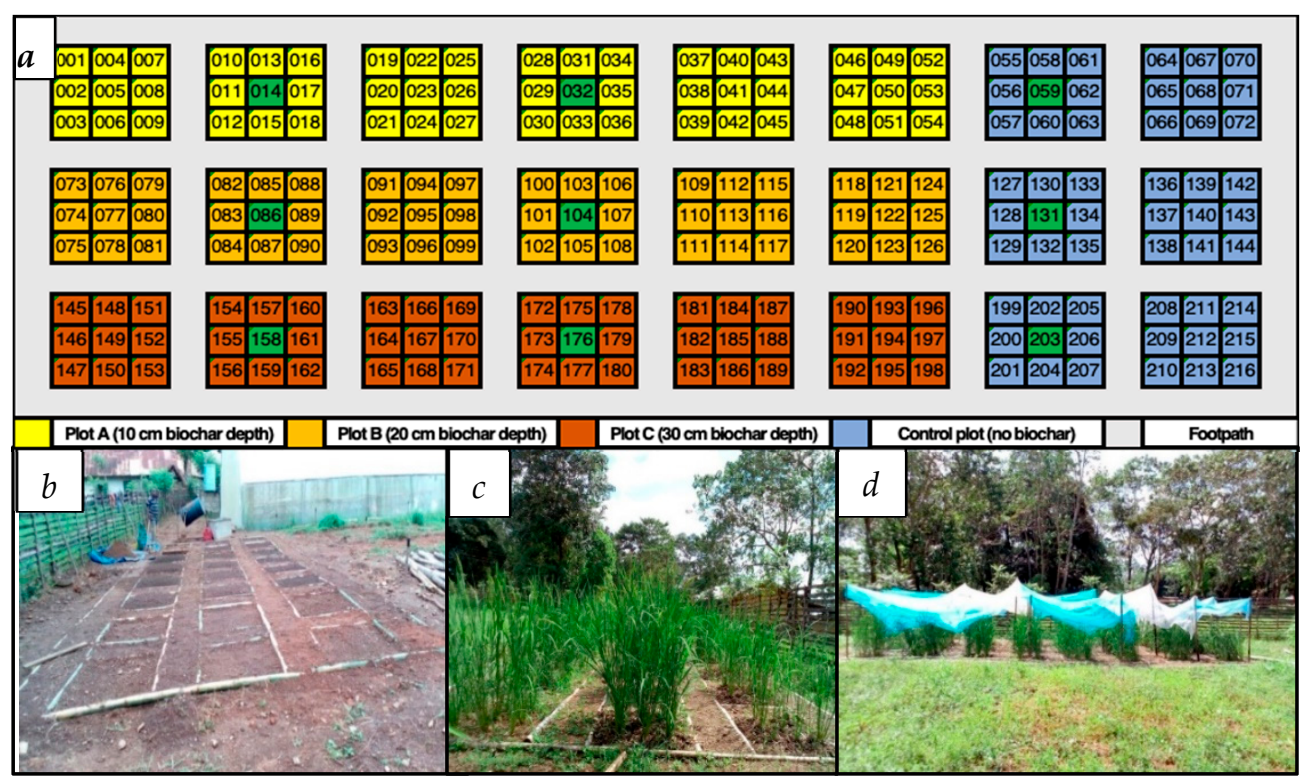

Figure 2. A sketch of the experimental field layout depicting the order of the rice plant hills in each plot (plate $a$ ). Note that the big box is the plot and each of the small boxes with the numbers represent a rice hills in the plot. The different colors in (plate $a$ ) indicate different biochar application depths and the green shades (plate $\boldsymbol{a}$ ) are the sampling points for soil moisture measurement. Plate $(\boldsymbol{b})$ is on-the-ground picture of the sketch in plate $(a)$. The next plates $(c)$ and $(d)$ show respectively the heading and milking growth stages of the NERICA-4 rice. Also note that the milking stage in plate $(d)$ is covered with mosquito net to prevent bird damage.

\subsection{Biochar-Soil Mixture and Depth Application}

In a previous experiment involving biochar treatment of the same soil, the 1:20 (5\%) biochar-soil ratio had the best effect on rice yield [32]. Thus in this study, the $5 \%$ biochar-soil ratio (by volume) was used for three different application depths: 0-10 cm (TA), 0-20 cm (TB), and 0-30 cm (TC). These depths were used because rice root hardly penetrates beyond $30 \mathrm{~cm}$ in the soil. Also the plow depth and depth of application of fertilizers or organic manure are mostly within this depth range.

For TA, the soil in the $1.0 \mathrm{~m} \times 1.0 \mathrm{~m}$ plot was dug out to the depth of $0.1 \mathrm{~m}$; i.e., a soil volume of $0.1 \mathrm{~m}^{3}$. The dug-out $0.1 \mathrm{~m}^{3}$ of soil was mixed with $0.005 \mathrm{~m}^{3}$ of biochar dust to have the $5 \%$ (1:20) biochar-soil mixture. The process was repeated for TB, where $0.2 \mathrm{~m}^{3}$ of soil dug out from the pit was mixed with $0.010 \mathrm{~m}^{3}$ biochar dust to have $5 \%$ (1:20) biochar-soil ratio. It was again repeated for TC, where $0.3 \mathrm{~m}^{3}$ of soil dug out from the pit was mixed with $0.015 \mathrm{~m}^{3}$ of biochar dust to get $1: 20(5 \%)$ biochar-soil ratio. No biochar was used in the control treatment (CK). Each treatment was replicated 6 times to get a total of 24 treatment plots and each plot planted in 9 hills of rice (a total of 216 hills). This meant that the study was a $1 \times 3$ factorial treatment (with one biochar-soil mixture applied in three depth variations) for a total of 3 treatments and then the control (Figure 2a).

\subsection{Agronomic Practices}

New Rice for Africa (NERICA) is a cultivar group of interspecific hybrid rice developed from the African Oryza glaberrima (high biomass) and Asian Oryza sativa (high yield) varieties by the Africa Rice Center (WARDA) to improve the yield of African rice cultivars. NERICA-4 rice cultivar is a high-tillering and high-yielding upland rice hybrid. Its strong vigor at seedling and vegetative stages with moderate tillering, intermediate height, high water logging resistance, and short duration (120 days) helps to successfully suppress weed. The seed rice was manually planted at equal row and column spacing of $25 \mathrm{~cm}$ and planting depth of $2 \mathrm{~cm}$ (Figure 2b). The experiment was done under rainfed conditions and therefore irrigation was not at any point considered in the study. The seed 
rice was planted on the 21st of July 2016 at 16:00 pm (Sierra Leone local time) and at a seeding rate of 4 seeds per hill and planting density of 9 hills per plot for each of the 24 plots. Then 4 weeks after planting, an organic growth booster (trade named D. I. Grow Fertilizer with N1.85\%:P1.85\%:K3.31\% + $\mathrm{Te}$ ) and the insecticide (Lara Force) were applied on the rice seedlings to boost growth and prevent pest infestation. The growth-booster fertilizer and pesticide treatments were repeated in the 6 th and 8th weeks after planting.

Hand weeding was done at the end of the 5th week and then tinning done to one seedling per hill in the 6th week. During thinning, only the most vigorous seedling was retained in each hill. Then NPK (15:15:15) fertilizer was applied in the row method, followed by mulching with grass straw. Because the experiment was conducted under rainfed condition, mulching moderated soil water loss through evaporation, suppressed weed growth, and prevented soil hardening and cracking during intermittent spells of no rainfall. Also fertilizers were applied to further boost the generally porous and poor soil for good crop growth, especially for the control treatment. The pesticide was also used to prevent pest damage because pests extremely strive under hot, humid tropical conditions.

Booting started at the end of the 9th week, followed by heading at the end of the 10th week (Figure 2c). During milking, the entire rice field was covered with mosquito tent (knitted together) by hooking it over bamboo cane poles to prevent bird damage and grain loss (Figure 2d). The rice was not ready for harvest until the end of the 14th week, probably due the cloudy and raining weather conditions.

At harvest, the panicle was first cut at the sheath point of the last leaf using penknife. Then the remaining rice stalk was uprooted from the soil for further treatment (including measurement of the various parameters).

\subsection{Data Collection}

Data were collected for various growth and yield parameters of the Nerica-4 rice plant, including both belowground (root length and weight) and aboveground (shoot height and weight, tiller number, panicle length, and grain weight) parameters. All the variables were measured at hill-scale. Soil moisture was gravimetrically measured at harvest, with samples taken from 2 plots per treatment, except for the control treatment where 3 plots were used (Figure 2a).

For crop height, measurements started at the end of the 4th week (using a graduated PVC box pipe) and repeated every 2 weeks until harvest at the end of the 14th week (which was on 4th November 2016). Tiller number count started at the end of the 6th week and also repeated every 2 weeks until harvest. With tillering, only the height of the tallest tiller in a hill was recorded. For the measurement involving weight, both fresh and dry weights were taken after harvest, although only dry weight was presented in this work. Again the data were taken at hill scale and since there was a large number of treatment hills (216 hills), samples were taken from the weighed fresh variables for dry weighing. The samples were tagged serially from 001 to 216, corresponding to the hill sequence in Figure 2a. The samples (of root, stem, panicle and grain) were again weighed fresh, oven-dried at $105^{\circ} \mathrm{C}$ for $92 \mathrm{~h}$ (to a constant weight) and then reweighed to get the dry weight. Then the per-hill dry weight was calculated (by wet weight) from the sample as:

$$
V_{d w h}=\left(\frac{S_{d w}}{S_{f w}}\right) \times V_{f w h}
$$

where $V_{d w h}$ is variable dry weight per hill [g]; $S_{d w}$ is sample dry weight [g]; $S_{f w}$ is sample fresh weight [g]; and $V_{f w h}$ is variable fresh weight per hill [g].

\subsection{Data Analysis}

The results were reported as mean and standard deviations (SD) of the variables. For statistical analysis, the data were first screened using the Dixon Outlier Test [44] and all outliers removed before 
processing for the mean and SD [45]. The SPSS (Statistical Package for Social Sciences) software, now renamed PASW (Predictive Analytics SoftWare), was used to analyze the data. The PASW software has powerful and efficient focal statistics and a wide global application [46].

Two-way analysis of variance (ANOVA) along with Student-Newman-Keuls (SNK) tests were conducted to isolate treatment (biochar depth) effects on crop productivity at the $99 \%(p=0.01)$ confidence level $[47,48]$. ANOVA F-statistic was used to measure variations within samples and ANOVA $p$-value to test the significance of the independent on the dependent variables. SNK, a stepwise multi-comparison procedure, was used to identify sample means with significant differences [49]. Furthermore, the interdependence of the crop parameters (grain yield against biomass yield, plant height against tiller number, tillers with panicle against tillers without panicle, etc.) was tested using regression analysis and the equations and determination coefficients $\left(R^{2}\right)$ shown on the plots. Also a table was dedicated to the correlativity of the variables.

\section{Results and Analysis}

\subsection{Crop Tiller and Length Dynamics}

Tiller count started at the end of the 6th week and was repeated every 2 weeks until the 14th week, which was the week of harvest. As in Figure 3a, the number of tillers increased with time from week 6 to week 10, after which it dropped. The number of tillers per hill was highest for TB (average of 10.56 tillers/hill), followed by TA, CK, and then TC treatment, in that order (Figure 3b). The average rate of tillering for all the treatments was 0.17 tillers/day, which was also highest for TB ( 0.19 tillers/day) and lowest for TC ( 0.15 tillers/day). Based on ANOVA and 2-tailed T-test analysis at $p=0.05$ confidence level, there was significant correlation $(r>0.97)$ between every paired combinations of the treatments but with significant difference, except for TA and CK. Generally, NERICA rice can grow 7-26 tillers per plant. Specifically, NERICA-4 (which is an upland rice cultivar) grown under rainfed conditions can produce an average of 12 tillers per plant [32,50]. The number of tillers in this study was 3-27, with an average of 10 tillers per plant.

The length of the NERICA-4 rice plant was measured along with that of the yield components, including root, shoot and panicle. Figure $3 c$ plots the measured plant growth from the 4 th to the 14th week after planting. Similar to tillering, growth was rapid until the 10 th week and almost stagnated until the 14th week. Unlike tillering, however, growth was strongest in CK $(132.96 \mathrm{~cm})$, followed by TB $(131.56 \mathrm{~cm})$, TC $(129.30 \mathrm{~cm})$ and then TA $(124.19 \mathrm{~cm})$ in that order (Figure 3d). The average height of the NERICA-4 rice cultivar is $120 \mathrm{~cm}$ [50], meaning the performance of the rice in terms of height was above average. The average growth rate was $1.85 \mathrm{~cm} /$ day and all the treatments strongly correlated $(r>0.99)$, but significantly different at the 0.05 confidence level (2-tailed T-test); except for TA/TC and TB/TC. From the plots on tiller number and plant height, it was not exactly clear that biochar application depth significantly improved the productivity of the rice crop under tropical rainfed conditions.

To understand the growth dynamics further, the lengths of some of the yield components were measured at harvest and plotted in Figure 4. Note that the trend line in Figure 4a is the sum of all the measured yield components, and that (which is the same as the value for plant length) in the bottom plate is the average across the treatments. From the plot, it was clear that with root length added, TA had the highest productivity in terms of plant length $(172.90 \mathrm{~cm})$. This was followed by TB, CK, and then TC had the shortest length (134.48). Generally, root length decreased with increasing biochar application depth, and root length under CK was higher than that under TC (the $30 \mathrm{~cm}$ biochar depth treatment). Also along the yield components, TA performed the best and TC the worst (Figure 4b). The length increased across the yield components from the root to the panicle, to the shoot and then to the entire plant (which was the sum of the other 3 yield components). TC had the shortest length, and it was the treatment most affected by insect/pests in the study. There was also mounding in TC, resulting from mixing the biochar with excavated soil to the depth of $30 \mathrm{~cm}$. This affected water infiltration and with possible negative effect on the performance of TC. 

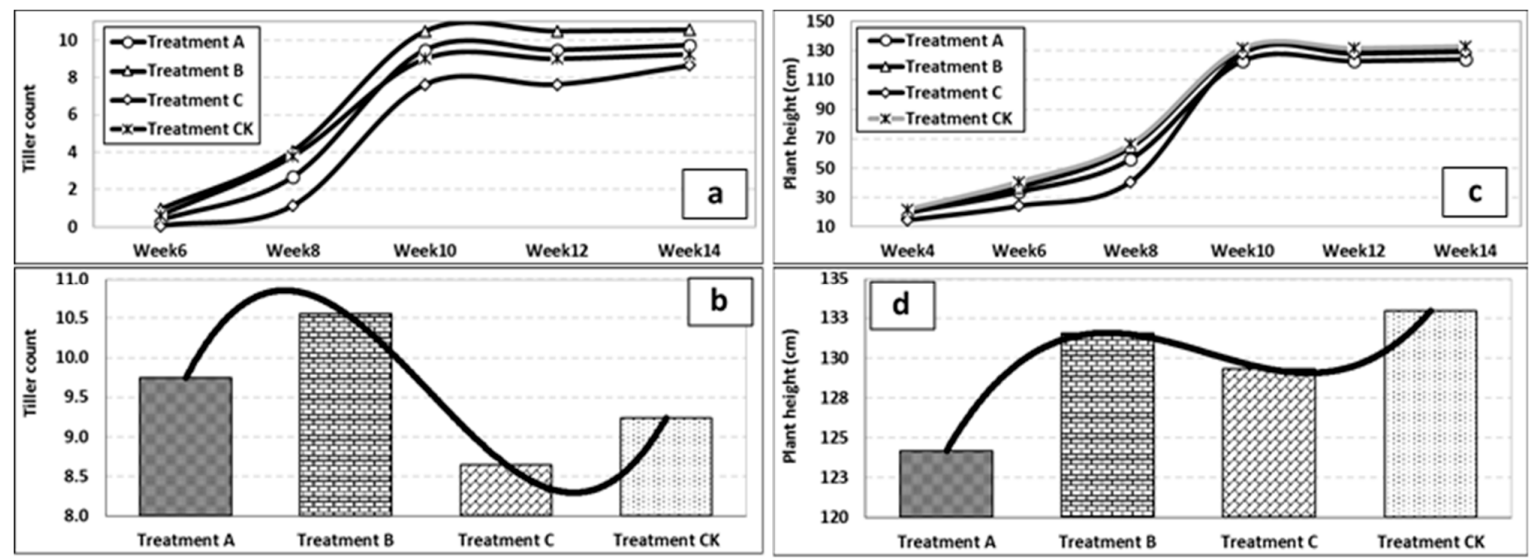

Figure 3. Number of tillers from the 6th to the 14th week (plots a \& b) and plant growth from the 4th to the 14th week (plots $\mathbf{c} \& \mathbf{d}$ ) of planting of New Rice for Africa (NERICA)-4 rice plant in 3 biochar application depths plus the control under tropical rainfed conditions. Treatments A, B, and C respectively denote the 10,20 , and $30 \mathrm{~cm}$ biochar application depths and then non-biochar treatment $(\mathrm{CK})$ is the control.

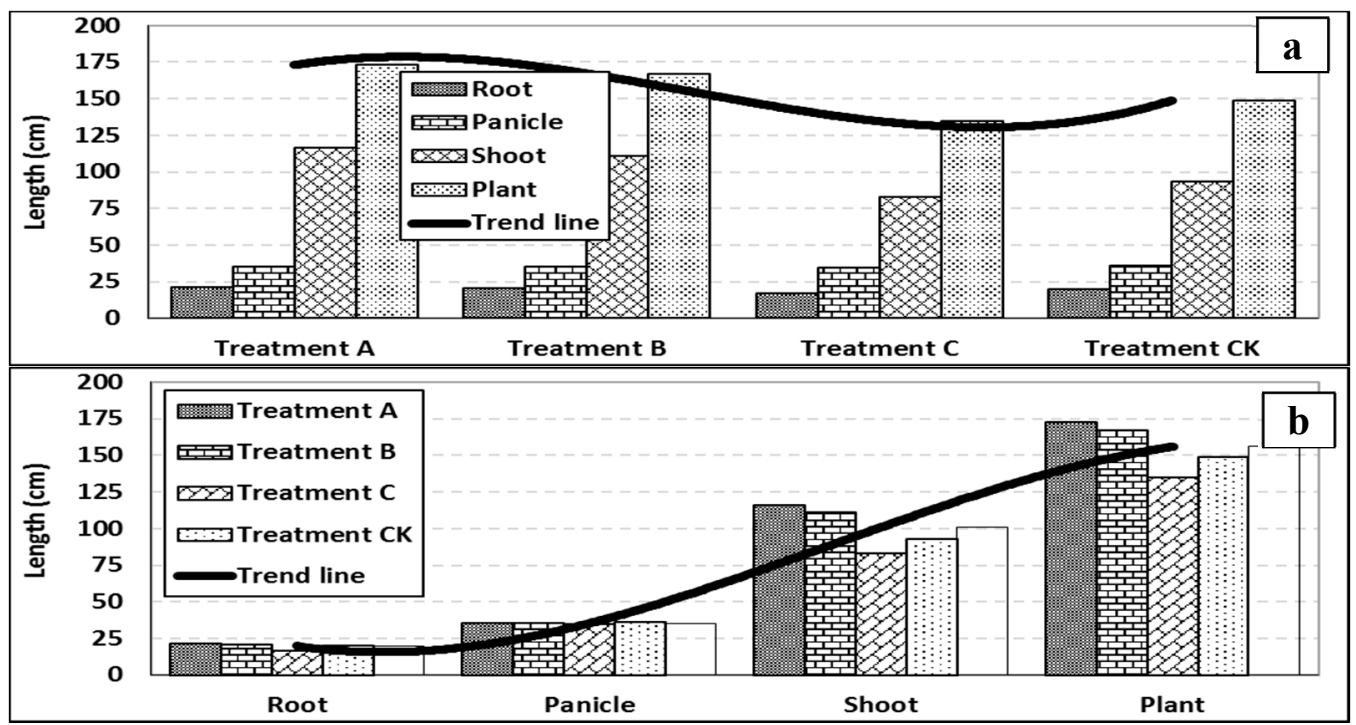

Figure 4. Length of NERICA-4 rice plant along the different treatments (a) and yield components (b). Treatments A, B, and C respectively denote the 10,20, and $30 \mathrm{~cm}$ biochar application depths and then $\mathrm{CK}$ is the control.

\subsection{Crop Weight Dynamics}

The weights of the various yield components of the NERICA-4 rice plant were taken at harvest, dried, reweighed, and the dry weight plotted in Figure 5. Note that the trend line in Figure 5a is the sum for the yield components (which is the same as the value for the plant), and that in the bottom plate (of Figure 5) is the average across the treatments. Based on the plot in Figure 5, yield weight was smallest at the root scale $(1302.56 \mathrm{~kg} / \mathrm{ha})$ and highest at the plant scale $(16,673.07 \mathrm{~kg} / \mathrm{ha})$. At the treatment scale, yield weight was highest under TB $(17,799.57 \mathrm{~kg} / \mathrm{ha})$ and lowest under TC $(14,521.25 \mathrm{~kg} / \mathrm{ha})$. Grain weight, which is among the most important yield components of rice, was highest under TB $(5704.45 \mathrm{~kg} / \mathrm{ha})$, followed by CK $(5222.32 \mathrm{~kg} / \mathrm{ha})$ and TA $(4791.87 \mathrm{~kg} / \mathrm{ha})$, and it was lowest under TC $(3910.07 \mathrm{~kg} / \mathrm{ha})$. For NERICA-4 rice cultivar, average grain weight is $5000 \mathrm{~kg} / \mathrm{ha}[32,50]$. This suggested that the plant performed above average for TB and CK, but below average for TA and TC. While the below-average performance of TA could be attributed to the shallow biochar application depth $(10 \mathrm{~cm}$, far below rice root penetration depth), that for TC was likely due to pest damage and mounding effect 
on the yield. In terms of dry weight, root accounted for $7.81 \%$, grain $29.43 \%$ and then shoot $62.76 \%$ of the NERICA-4 rice plant.

Despite the good correlation $(r>0.74)$, 2-tailed T-test analysis showed significant differences (at $p=0.05$ ) among all paired combinations of the parameters along crop yield components. However, there was strong correlation $(r>0.99)$ and no significant differences (at $p=0.05)$ among paired combinations of the treatments for the yield weights. Based on ANOVA analysis, the treatments did not have any significant effect on yield weight, but the yield components were indeed significantly different in terms of weight. It is good to note, however, that yield component is partly a genetic factor that controls root, shoot and grain ratio, irrespective of the treatment.

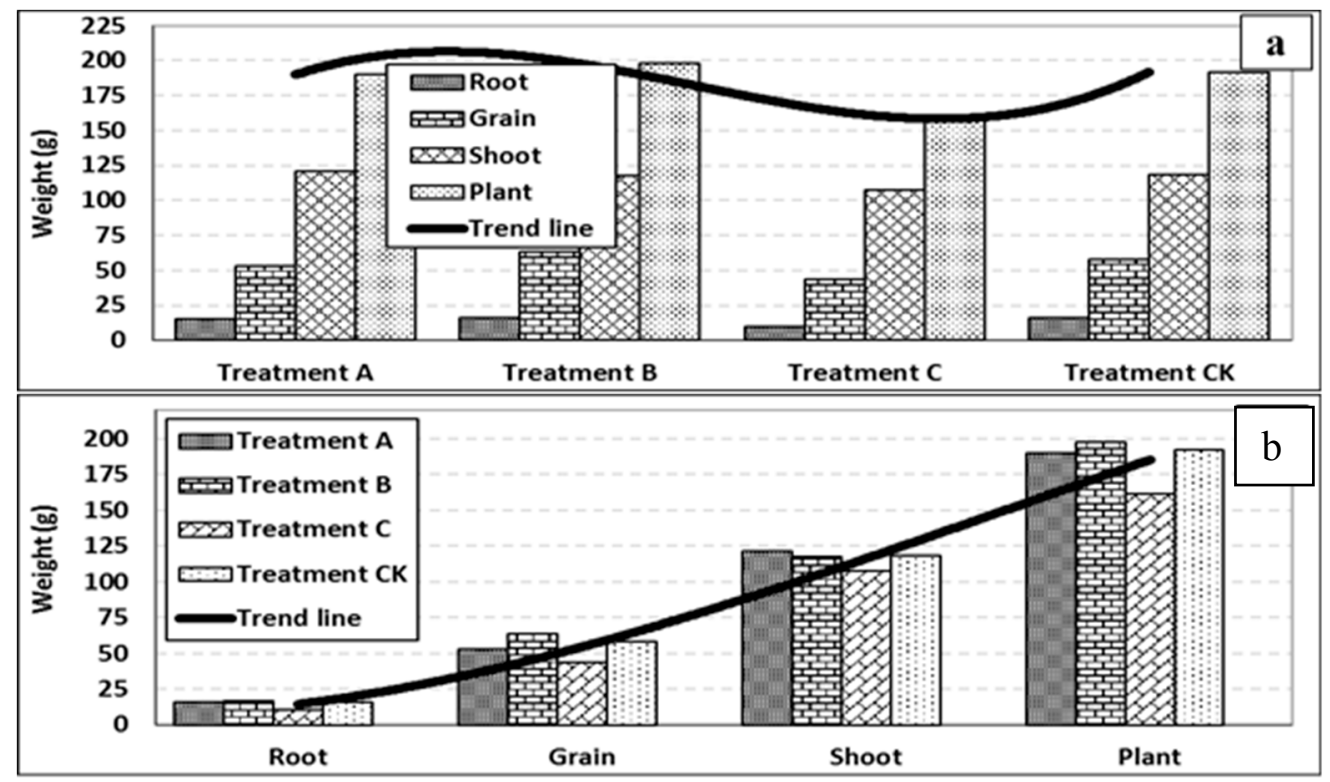

Figure 5. (a) Weight of NERICA-4 rice plant along different treatments; (b) yield components. Treatments A, B, and C respectively denote the 10,20 , and $30 \mathrm{~cm}$ biochar application depths and then $\mathrm{CK}$ is the control.

\subsection{Crop and Soil Moisture Dynamics}

From the measured fresh and dry weights of the yield components of the NERICA-4 rice cultivar, crop moisture content was determined using Equation (1) and plotted in Figure 6a,b. Also in Figure $6 c$ is the soil moisture content calculated from soil samples taken from the treatment plots (see the materials and method section). Note that the trend lines in Figure 6 depict the average values across either the treatments or the yield components.

For crop moisture content across the treatments (Figure 6a), moisture content was highest under TB $(44.01 \%)$, followed by TC (37.14\%), CK $(36.87 \%)$, and then TA $(33.75 \%)$. Also for crop moisture content across yield components (Figure $6 \mathrm{~b}$ ), it was highest for shoot $(49.18 \%)$, followed by root $(40.18 \%)$, the whole plant $(37.94 \%)$, and then the grain $(24.47 \%)$. Then for soil moisture content across the treatments (Figure $6 \mathrm{c})$, it was highest under TA (15.79\%), followed by TB $(15.58 \%)$, CK $(15.17 \%)$, and then TC $(14.98 \%)$.

For crop moisture content across treatment combinations, there was strong correlation $(r>0.99)$ between every paired combination of the treatments. However, none of the correlations was significant at $p=0.05$. For crop moisture content across yield component combinations, there was no correlation $(r=0.45-0.47)$ between 2 of the paired yield component combinations (grain, root and grain, shoot) but there was correlation $(r=0.67-0.87)$ between the other paired yield-component combinations. ANOVA analysis showed that except for the root, shoot and root, plant yield-component combinations, there were significant $(p=005)$ differences in crop moisture content at the yield scale. Then at treatment 
scale for soil moisture content, all the paired combinations were correlated $(r=0.73-0.99)$ but none was significant at $p=0.05$; except for the TA, TC $(p=0.02)$, and TB, CK $(p=0.03)$ treatment combinations.

While the differences in both the crop and soil moisture contents was attributable to treatment and genetic factors, also field conditions (that were not part of the treatment) possibly contributed to the differences. For instance, the separation of the treatment plots by bamboo canes caused water logging in TA and CK treatments during rainfall events. Also mixing biochar with dug-out soil caused mounding after backfilling under TC (the treatment with the highest depth, $30 \mathrm{~cm}$ ), limiting infiltration during rainfall events. These field conditions in combination with treatment effects and genetic factors contributed to the differences in both the soil and crop moisture contents in the study. This necessitated screening for the three factors (genetic, treatment, and field condition) with the highest impact on the observed discrepancies.

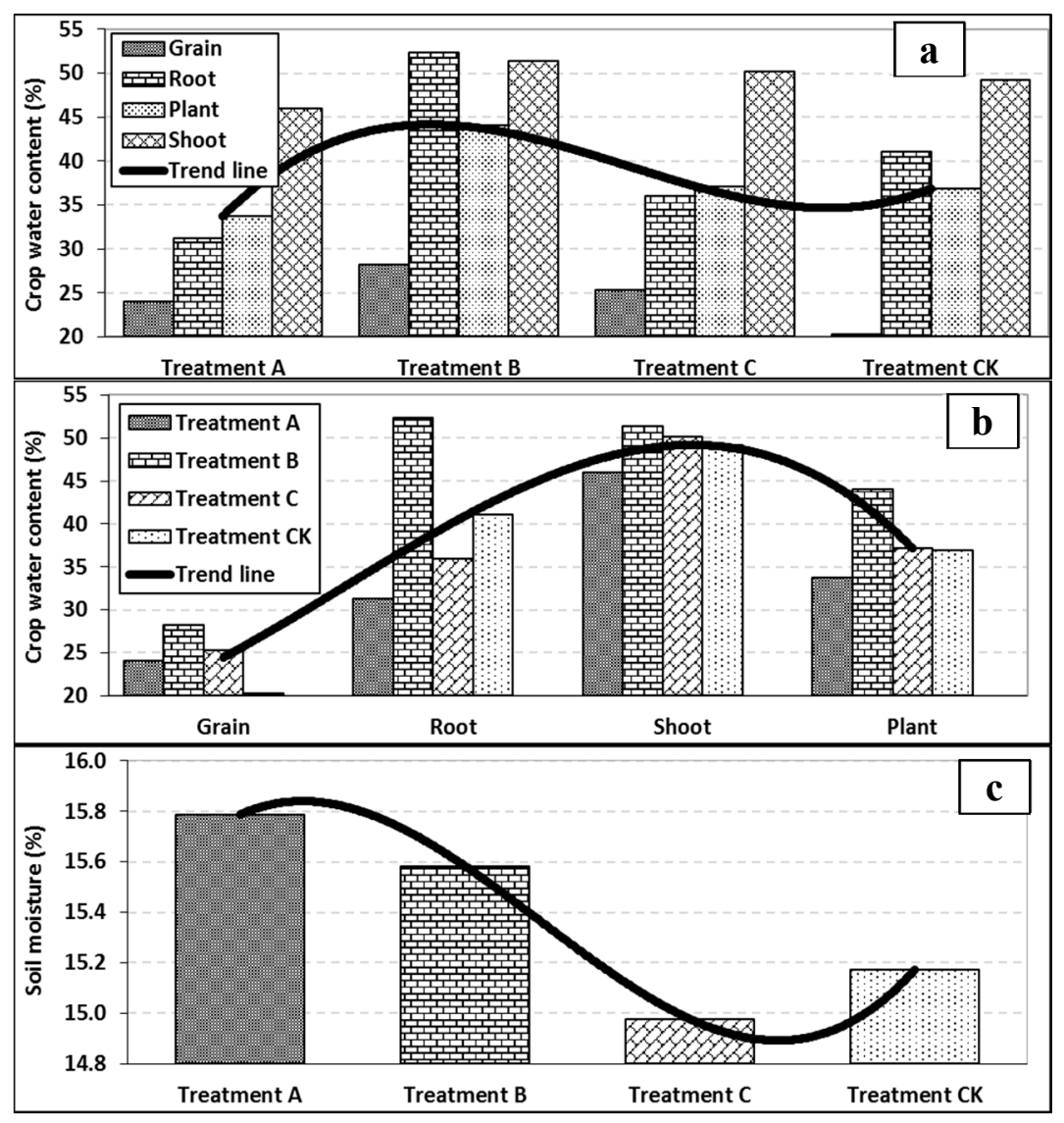

Figure 6. Moisture content of NERICA-4 rice plant along the different treatments (a), yield components (b) and that of the soil along the treatments (c). Treatments A, B, and C respectively denote the 10, 20, and $30 \mathrm{~cm}$ biochar application depths and CK is the control.

\subsection{Parameter Correlativity}

The coefficients of determination $\left(R^{2}\right)$ for paired combinations of the yield components are given in Table 1. With the exception of just 4 paired combinations (TN, SL; TN, RL; TN, PL, and TN, CM; where TN is tiller number, SL shoot length, RL root length, PL panicle length, and CM crop moisture content), all the measured yield components were strongly correlated. In fact, perfect correlations $\left(R^{2}=1.00\right)$ existed between 9 of the paired yield components. Despite the strong correlations, however, 2-tailed T-test showed that some of the variables (italicized values) had significant differences (and that was mostly with panicle weight, PW). This suggested that the yield components were largely interdependent. Only 2 of the paired variables (TN, RL and TN, CM; underlined in Table 1) had 
negative correlation. For instance, the number of tillers (and especially tillers with grains) influenced the quantity of grains produced $\left(R^{2}=0.89\right)$.

Table 1. A table of correlativity of yield component variables of NERICA-4 upland rice. In the table, $\mathrm{TN}=$ tiller number, $\mathrm{GW}=$ grain weight, $\mathrm{SW}=$ shoot weight, $\mathrm{SL}=$ shoot length, $\mathrm{RW}=$ root weight, $\mathrm{RL}=$ root length, $\mathrm{PW}=$ panicle weight , and $\mathrm{PL}=$ panicle length and $\mathrm{CM}$ crop moisture content.

\begin{tabular}{cccccccccc}
\hline $\boldsymbol{R}^{\mathbf{2}}$ & TN & GW & SW & SL & RW & RL & PW & PL & CM \\
\hline TN & 1.00 & & & & & & & & \\
GW & 0.89 & 1.00 & & & & & & & \\
SW & 0.84 & 0.99 & 1.00 & & & & & & \\
SL & 0.19 & 0.91 & 0.93 & 1.00 & & & & & \\
RW & 0.94 & 0.94 & 0.99 & 0.96 & 1.00 & & & & \\
RL & 0.00 & 0.89 & 0.91 & 1.00 & 0.96 & 1.00 & & & \\
PW & 0.90 & 1.00 & 1.00 & 0.95 & 1.00 & 0.97 & 1.00 & & \\
PL & 0.19 & 0.91 & 0.93 & 1.00 & 0.97 & 1.00 & 0.98 & 1.00 & \\
CM & 0.14 & 0.88 & 0.92 & 1.00 & 0.96 & 1.00 & 0.98 & 1.00 & 1.00 \\
\hline
\end{tabular}

\section{Discussions}

\subsection{Biochar Research}

Maintaining appropriate levels of nutrient cycle is key for successful soil management efforts in humid tropical regions. Cover crop, mulch, compost or manure additions supply nutrients to crops, shorten nutrient cycle by increasing microbial biomass activity and hold onto applied mineral fertilizers [51,52]. However, none of these seem to have a long-term effect like biochar. Biochar research regained momentum with the discovery of the Amazonian terra preta soils in the endless search for sustainable agriculture and worsening climate change. The terra preta soil is today widely studied for reproduction and application in soil amendment because of its huge potential for nutrient/carbon capture and storage [16]. The biochar-rich terra preta soils in the Amazon occur in various depths and spatial extents and are also highly potent in nutrient and carbon, and can therefore support strong vegetation growth. While biochar studies have mostly focused on the production modes and application rates, little has been done on the application depth. This study was set up to determine the effect of biochar application depth on crop productivity under tropical rainfed conditions. A fixed soil-biochar volume ratio of 1:20 (5\% biochar) was applied in 3 depths-TA $(10 \mathrm{~cm}), \mathrm{TB}(20 \mathrm{~cm})$, and TC $(30 \mathrm{~cm})$-and investigated against a control treatment $(\mathrm{CK})$ with no biochar.

\subsection{Treatment Effect on Yield}

Based on the results, the number of tillers per hill was highest under TB, followed by TA, CK, and then TC. The increase in the number of tillers in successive time periods ( 2 weeks in this case) were strongly correlated $(r>0.85)$, but only significantly different $(p=0.05)$ for the period from the 6th to the 8 th week and then from the 8 th to the 10 th week (Figure $3 a, b$ ). Tillering was not completely consistent with biochar application depth, probably due to field contingencies (pest damage and water logging) under the tropical rainfed condition.

For the shoot system, increase in plant height in successive time periods (also 2 weeks in this study) was strongly correlated ( $r>0.96)$, except for the period between the 8th and 10th weeks $(r=0.41)$. Also 2-tailed T-test showed that the differences in the increase in height between the successive time periods were significant at the 0.05 confidence interval. On average, plant height was highest under CK (control treatment), followed by TB, TC, and TA (Figure 3c,d). Like tillering, plant height was not completely consistent with biochar application depth and probably affected by the same contingent field conditions.

For plant length (which is the total length for root, shoot and panicle), it decreased with increasing biochar application depth (Figure 4). However, plant length under CK (no biochar) was higher than 
that under TC ( $30 \mathrm{~cm}$ biochar depth). On average, the rice plant increased from root to panicle (cut from the last leaf base) and then to shoot (without panicle). Genetically, rice shoot is longest, followed by panicle and then root (Figure 4). The approximate ratio of panicle-to-root was 1:2, shoot-to-panicle was 1:3, and panicle-to-shoot was 1:5.

The observed field contingencies included water logging, which was highest in CK (where there was no tillage), followed by TA (10 cm tillage depth plus biochar), but no water logging in TB $(20 \mathrm{~cm}$ tillage depth plus biochar), but even mounding in TC (30 cm tillage depth plus biochar). The differential water logging condition was because with no tillage (CK), the bamboo canes around the plots caused sunken beds to develop. Under TA, the addition of only 1 part of biochar to 20 parts of dug-out soil to the depth of $10 \mathrm{~cm}$ increased little the backfill volume and therefore sunken beds also formed after using separation bamboo canes. Under TB, the increase in volume due to the mixing of the $20-\mathrm{cm}$ depth of soil with biochar caused the bed to just level out with the separation canes and there was therefore no water logging. Finally, under TC, the increase in volume due to the mixing of $30 \mathrm{~cm}$ depth of excavated soil with biochar cause mounding above the separation canes, causing runoff. As a key factor for rice growth, the differential water conditions of the treatment plots affected the crop yield. Also, because no buffer plots were put around the treatment plots, pest out outbreak affected more the peripheral TA (which bordered on vegetable plots) and TC (which bordered on bush) treatment plots. Pest outbreak was highest in TC, followed by TA, but almost not in TB and CK treatments. The pest damage also contributed to the inconsistencies in the measured plant height and length along the experimental treatments.

The total plant weight (i.e., root, shoot with panicle and grain) was highest for TB, followed by CK, then TA and finally TC (Figure 5). In terms of the measured yield components, weight increased from root to grain and then to shoot. Root accounted for $7.81 \%$ of the total plant weight, grain $29.43 \%$ and then shoot (with panicle) $62.76 \%$. Especially for grain (which is the most important yield component for rice), it was highest for $\mathrm{TB}$, followed by $\mathrm{CK}$, TA, and then TC. While shoot weight was highest for $\mathrm{TA}$, grain weight and root weight were highest for CK. Weight was not consistent along the treatments (either way from TA to TB to TC) probably because of the negative effect of the contingent field conditions explained above.

For crop moisture content, it was highest under TB, followed by TC, CK, and then TA. For the measured yield components, it was highest under TB and lowest under TA for root and shoot. Then for grain, moisture content was highest under TB and lowest under $\mathrm{CK}$. The percent contributions of grain, root and shoot (plus panicle) to the total moisture content of the rice plant were $21.50 \%, 35.30 \%$, and $43.21 \%$, respectively. For soil moisture content, it was simply highest for TA, followed by TB, then CK and lowest for TC. Irrespective of the inconsistencies in the measured variables along the treatments (probably due to the contingent field conditions), there were strong correlations among most of the paired combinations of the variables (Table 1).

\subsection{Field Contingency Effect on Yield}

To further understand the effect of the contingent field conditions on the performance of the measured yield variables, a table of the best- and worst-performing treatments was constructed (Table 2). Note that plant weight $(\mathrm{PW})$ and height $(\mathrm{PH})$ constituted of the sum of the values of all the measured yield components (root, shoot, panicle and grain), and therefore not separately given. Thus, from Table 2, it was apparent that under high soil moisture (SM) content, water was not a factor for the performance of the measured yield variables (MYV), except plant length (PL). Conversely under low soil moisture content, water became critical for the performance of all the measured yield variables, except crop water content (CW). This suggested that rice plant always adjusted its own tillering (TN), growth (measured as PL) and dry matter accumulation (measured as PW) to maintain a certain level of water to keep alive. Soil moisture content was lowest under TC because of mounding (raised bed), implying that most of the soil moisture was absorbed to sustain growth under TC. Furthermore, large plant length was influenced only by soil moisture, whereas small plant length was a function of soil 
moisture, tiller number, and plant weight. While low tiller number was affected by all the measured yield variables, except crop water content, high tiller number was a function of both crop water content and plant weight.

Table 2. A table depicting the match of the biochar depth treatments (BDT) with the highest and lowest values of the measured yield variables (MYV) of NERICA-4 rice plant under tropical rainfed conditions.

\begin{tabular}{cccccccc}
\hline \multirow{2}{*}{ MYV } & \multirow{2}{*}{ BDT } & \multirow{2}{*}{ Level } & \multicolumn{5}{c}{ MYV Match } \\
\cline { 4 - 8 } & & & TN & PW & PL & CW & SM \\
\hline \multirow{2}{*}{ TN } & TB & Highest & $\sqrt{ }$ & $\sqrt{ }$ & $\times$ & $\sqrt{ }$ & $\times$ \\
& TC & Lowest & $\sqrt{ }$ & $\sqrt{ }$ & $\sqrt{ }$ & $\times$ & $\sqrt{ }$ \\
PW & TB & Highest & $\sqrt{ }$ & $\sqrt{ }$ & $\times$ & $\sqrt{ }$ & $\times$ \\
& TC & Lowest & $\times$ & $\sqrt{ }$ & $\sqrt{ }$ & $\times$ & $\sqrt{ }$ \\
PL & TA & Highest & $\times$ & $\times$ & $\sqrt{ }$ & $\times$ & $\sqrt{ }$ \\
& TC & Lowest & $\sqrt{ }$ & $\sqrt{ }$ & $\sqrt{ }$ & $\times$ & $\sqrt{ }$ \\
CW & TB & Highest & V & $\sqrt{ }$ & $\times$ & $\sqrt{ }$ & $\times$ \\
& TA & Lowest & $\times$ & $\times$ & $\times$ & $\sqrt{ }$ & $\times$ \\
SM & TA & Highest & $\times$ & $\times$ & $\sqrt{ }$ & $\times$ & $\sqrt{ }$ \\
& TC & Lowest & $\sqrt{ }$ & $\sqrt{ }$ & $\sqrt{ }$ & $\times$ & $\sqrt{ }$ \\
\hline
\end{tabular}

Note that $\mathrm{TA}=$ treatment $\mathrm{A}$ (with $10 \mathrm{~cm}$ biochar application depth), $\mathrm{TB}=$ treatment $\mathrm{B}$ (with $20 \mathrm{~cm}$ biochar application depth), TC = treatment $C$ (with $30 \mathrm{~cm}$ biochar application depth) and $C K$ is control treatment (with no biochar). The measured yield variables include TN = tiller number, $\mathrm{PH}=$ plant height, $\mathrm{PW}=$ plant weight, $\mathrm{PL}=$ plant length, $\mathrm{CM}=$ crop moisture content, $\mathrm{SM}=$ soil moisture content, $\sqrt{ }=\mathrm{a}$ match, and $\times=$ no match. Double underline means treatment with water logging (due to the development of sunken) and limited pest infestation whereas italicized bold means treatment with runoff (due to mounding) and high pest infestation.

When related with the contingent field conditions, it was clear that TC (the 30-cm depth treatment with mounding runoff and high pest damage) had the lowest value for the measured yield variables, except crop water content (Table 2). Also, while low crop water content was not really a growth and yield factor, high crop water content influenced both tiller number and plant weight, but not plant length. Here again, soil moisture content had no effect on crop water content. Table 2 also showed that while TA $(10-\mathrm{cm}$ depth treatment with high water logging and limited pest damage) was lowest only for crop water content, TB (20-cm depth treatment with no water logging or pest damage) was highest for all the measured yield components, except plant length. This reaffirmed the point that the contingent field conditions affected the results of the experiment. Deductively therefore, it was possible that biochar application depth had a boosting effect on the performance of NERICA-4 rice cultivar. This was because for most of the time, TB $(20-\mathrm{cm}$ biochar depth treatment with no pest damage) performed better than CK (control treatment with water logging and no biochar or pest damage).

\subsection{Contingent Field Condition and Biochar Treatment Effects}

To quantify the effects of the contingent field conditions and the biochar application depth on the measured yield components, simple relational equations were developed. For this purpose, it was assumed that the effect of water logging, wherever it occurred, was the same. Similarly, the effect of pest damage, wherever it occurred, was the same too. Then while water logging and biochar application were yield-gain factors, pest damage was a yield-loss factor. With this, we then take the effect of water logging on the crop performance to be $w$, that of pest damage be $p$ and that of biochar depth be $b$. Based on field observations, there was water logging in CK $(C K \rightarrow w)$, water logging, biochar use and pest damage in TA $(T A \rightarrow w+b-p)$, biochar use in TB $(T B \rightarrow b)$ and then biochar use and pest damage in TC $(T C \rightarrow b-p)$. It then becomes apparent that $T A-T C=w$ and that $C K-w=\overline{C K}$ (where $\overline{C K}$ is crop yield without the effects of water logging, biochar use and pest damage). Also $T C-T B=-p$ (where $p$ is a yield loss factor and therefore negative). With $w$ and $p$ known, then $b$ can be derived from $\mathrm{T} A \rightarrow w+b-p$; thus $b=T A-\overline{C K}-w+p$. Note that TA, TB, TC and CK are used as defined earlier. 
Using the above relations for plant weight (PW), there was 20.30\% yield loss under TA due to pest damage, $36.84 \%$ yield loss under TB due to runoff (which indicates no water logging), $86.74 \%$ yield loss under TC due both to pest damage and runoff and then $14.86 \%$ yield gain under CK due to water logging. Similarly for plant length (PL), there was $4.98 \%$ yield loss under TA due to pest damage, $38.98 \%$ yield loss under TB due to runoff, $83.29 \%$ yield loss under TC due both to pest damage and runoff, and then $25.73 \%$ yield gain under CK due to water logging. Then finally for tiller number (TN), there was $14.45 \%$ yield loss under TA due to pest damage, $36.14 \%$ yield loss under TB due to runoff, $73.02 \%$ yield loss under TC due both to pest damage and runoff and then $11.82 \%$ yield gain under $\mathrm{CK}$ due to water logging. Yield loss or gain for crop water content $(\mathrm{CW})$ was not quantified because Table 2 suggested that it had no effect on the output of the rice crop. This implied that the minimum crop water requirement for growth was available throughout the experimental study.

After adjustment for the calculated values (i.e., after removal of the effects of pest damage and water logging on the biochar depth treatments), the effects of only the different biochar application depth treatments on the NERICA-4 rice yield are plotted in Figure 7 for the yield components including plant weight, plant length and tiller number. The plot showed that the rice crop yield increased with increasing biochar application depth and it was generally higher in biochar than in non-biochar treatments. From Figure 4, the measured root length was lowest in TC $(19.77 \mathrm{~cm})$ and longest in TA $(21.54 \mathrm{~cm})$. It then suggested that the rice root penetrated far beyond the 10-cm depth of biochar in TA, but that only halfway through the $30-\mathrm{cm}$ biochar depth in TC. Thus, biochar generally limited root penetration depth, probably because of sufficient availability of nutrients in the upper layers of the soil where the biochar was concentrated.

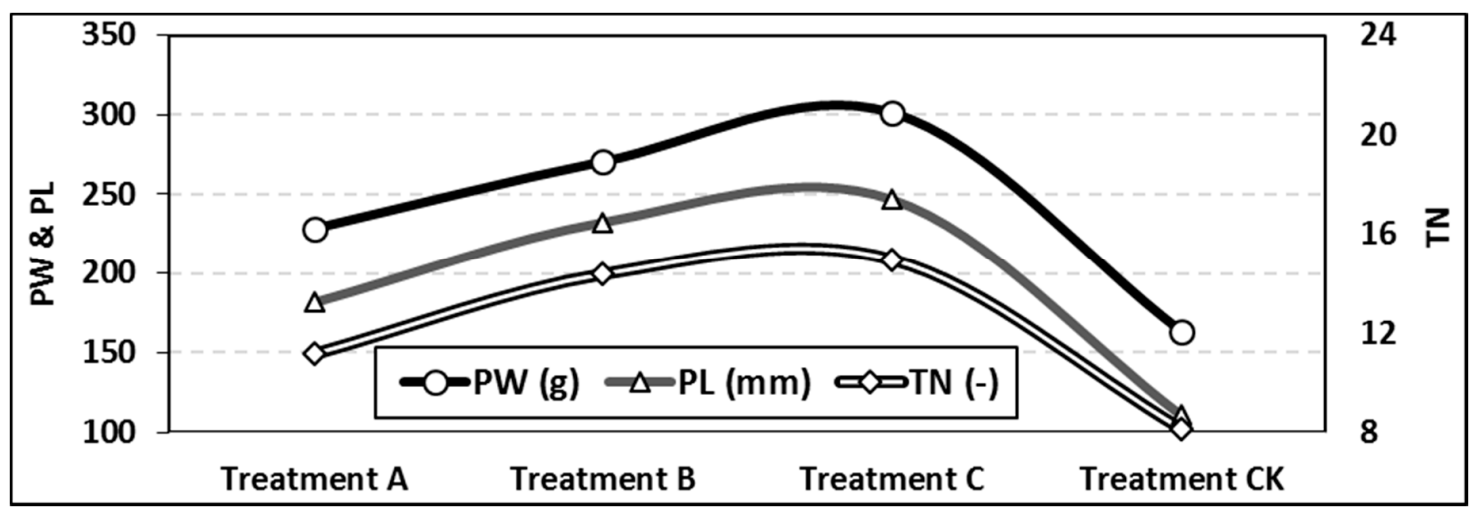

Figure 7. Plot depicting the trends in the effect of biochar depth on selected rice yield components after removal of the effects of contingent field conditions of water logging and pest damage. Note that $\mathrm{PW}=$ plant weight, $\mathrm{PL}=$ plant length, and $\mathrm{TN}=$ tiller number.

\section{Conclusions}

This study was set up to investigate the effect of biochar application depth on NERICA-4 upland rice cultivar under tropical rainfed conditions. Based on the study, biochar application not only boosted rice growth, but also increased rice yield with increasing application depth. There were different modes of biochar application, either as dust or lump or surface broadcasting or deep tillage. The results of the pilot study reconstructed from the formula developed suggested that the effects of biochar on crop growth and productivity also vary with the mode of application. Based on this study, the appropriate depth of application (which can vary with crop type) was critical for desired effects of biochar on crop productivity. With sufficient biochar in the soil, crop rooting depth can be reduced as biochar can create sufficient reserve of nutrients within the zone of application.

Importantly, however, contingent field conditions (including water logging, runoff, and pest damage) can variously affect rice plant growth. Although contingent field conditions were quantified in this study, sound experimental designs were needed to preclude damage due to any such conditions. 
For instance, since disease and pest outbreaks often start at peripheral plots, it is necessary to keep reasonable buffers around experimental plots to have sufficient time for effective action in the event of any such outbreaks. Despite all of this, the study showed that deep soil tillage with biochar was a more productive mode of cultivation than shallow or even surface applications under tropical rainfed conditions.

Author Contributions: J.P.M. conceived and designed the experiment and wrote the report; A.W. conducted the experiment and analyzed the data; M.M.B. analyzed and reviewed the data; M.P.N. financed the experiment; and R.S. financed the publication.

Funding: This research received no external funding.

Acknowledgments: We are grateful for the advice from the field technicians in the Department of Agricultural and Biosystems Engineering, Njala University, Sierra Leone.

Conflicts of Interest: The authors declare no conflict of interest.

\section{References}

1. Bridgwater, A.V. Renewable fuels and chemicals by thermal processing of biomass. Chem. Eng. J. 2003, 91, 87-102. [CrossRef]

2. Bridgwater, A.V. Review of fast pyrolysis of biomass and product upgrading. Biomass Bioenergy 2012, 38, 64-94. [CrossRef]

3. Lehmann, J. Terra preta nova—Where to from here? In Amazonian Dark Earths: Wim Sombroek's Vision; Woods, W.I., Wenceslau, G., Teixeira, W.G., Lehmann, J., Steiner, C., Winkler-Prins, A., Rebellato, L., Eds.; Springer Science: Berlin, Germany, 2009; p. 520.

4. Bian, R.; Joseph, S.; Cui, L.; Pan, G.; Li, L.; Liu, X.; Zhang, A.; Rutlidge, H.; Wong, S.; Chia, C.; et al. A three-year experiment confirms continuous immobilization of cadmium and lead in contaminated paddy field with biochar amendment. J. Hazard. Mater. 2014, 272, 121-128. [CrossRef]

5. Graber, E.R.; Tsechansky, L.; Mayzlish-Gati, E.; Shema, R.; Koltai, H. A humic substances product extracted from biochar reduces Arabidopsis root hair density and length under P-sufficient and Pstarvation conditions. Plant Soil. 2015, 395, 21-30. [CrossRef]

6. Skjemstad, J.O.; Clarke, P.; Taylor, J.A.; Oades, J.M.; Mcclure, S.G. The chemistry and nature of protected carbon in soil. Aust. J. Soil Res. 1996, 34, 251-271. [CrossRef]

7. Skjemstad, J.O.; Reicosky, D.C.; Wilts, A.R.; McGowan, J.A. Charcoal carbon in U.S. agricultural soils. Soil Sci. Soc. Am. J. 2002, 66, 1249-1255. [CrossRef]

8. Barrow, C.J. Biochar: Potential for countering land degradation and for improving agriculture. Appl. Geogr. 2012, 34, 21-28. [CrossRef]

9. Chan, K.Y.; Van Zwieten, L.; Meszaros, I.; Downie, A.; Joseph, S. Agronomic values of greenwaste biochar as a soil amendment. Aust. J. Soil Res. 2007, 45, 629-634. [CrossRef]

10. Spokas, K.A.; Cantrell, K.B.; Novak, J.M.; Archer, D.W.; Ippolito, J.A.; Collins, H.P.; Boateng, A.A.; Lima, I.M.; Mekuria, W.; Noble, A. The role of biochar in ameliorating disturbed Soils and sequestering soil carbon in tropical agricultural production systems. Appl. Environ. Soil Sci. 2013, 1-10. [CrossRef]

11. Laird, D.A. The Charcoal Vision: A win-win-win scenario for simultaneously producing bioenergy, permanently sequestering carbon, while improving soil and water quality. Agron. J. 2008, 100, 178-181. [CrossRef]

12. Novak, J.M.; Lima, I.; Gaskin, J.W.; Steiner, C.; Das, K.C.; Ahmedna, M.; Rehrah, D.; Watts, D.W.; Busscher, W.J.; Schmobert, $\mathrm{H}$. Characterization of designer biochars produced at different temperatures and their effects on a lomay sand. Ann. Environ. Sci. 2009, 3, 195-206.

13. Atkinson, C.J.; Fitzgerald, J.D.; Hipps, N.A. Potential mechanisms for achieving agricultural benefits from biochar application to temperate soil: A review. Plant Soil 2010, 337, 1-18. [CrossRef]

14. Haefele, S.M.; Konboon, Y.; Wongboon, W.; Amarante, S.; Maarifat, A.A.; Pfeiffer, E.M.; Knoblauch, C. Effects and fate of biochar from rice residues in rice-based systems. Field Crop. Res. 2011, 121, 430-440. [CrossRef]

15. Ahmad, M.; Rajapaksha, A.U.; Lim, J.E.; Zhang, M.; Bolan, N.; Mohan, D.; Vithanage, M.; Sang Soo Lee, S.S.; Ok, Y.S. Biochar as a sorbent for contaminant management in soil and water: A review. Chemosphere 2014, 99, 19-33. [CrossRef] [PubMed] 
16. Lehmann, J.; Gaunt, J.; Rondon, M. Bio-char sequestration in terrestrial ecosystems e a review. Mitig. Adapt. Strateg. Glob. Chang. 2006, 11, 403-427. [CrossRef]

17. Glaser, B.; Haumaier, L.; Guggenberger, G.; Zech, W. The Terra Preta phenomenon: A model for sustainable agriculture in the humic tropics. Die Nat. 2001, 88, 37-41. [CrossRef]

18. Grossman, J.M.; O’Neill, B.E.; Tsai, S.M.; Liang, B.; Neves, E.; Lehmann, J.; Thies, J.E. Amazonian anthrosols support similar microbial communities that differ distinctly from those extant in adjacent, unmodified soils of the same mineralogy. Environ. Microbiol. 2010, 60, 192-205. [CrossRef]

19. Mishra, B.K.; Ramakrishnan, P.S. Slash and burn agriculture at higher elevations in North-Eastern India. I. Sediment, water and nutrient losses. Agric. Ecosyst. Environ. 1983, 9, 69-82. [CrossRef]

20. Brewer, C.E. Biochar Characterization and Engineering. Graduate Theses and Dissertations, Paper 12284. Iowa State University, Ames, IA, USA, 2012. Available online: http://lib.dr.iastate.edu/etd (accessed on 4 February 2019).

21. Glaser, B.; Woods, W.I. Amazonian Dark Earths: Explorations in Space and Time; Springer: Berlin, Germany, 2004.

22. Lehmann, J.; Kern, D.C.; Glaser, B.; Woods, W.I. Amazonian Dark Earths: Origins, Properties, Management; Kluwer Academic: Dordrecht, The Netherlands, 2003.

23. Keech, O.; Carcaillet, C.; Nilsson, M.C. Adsorption of alleopathic compounds by wood-derived charcoal; the role of wood porosity. Plant Soil 2005, 272, 291-300. [CrossRef]

24. Glaser, B.; Lehmann, J.; Zech, W. Ameliorating physical and chemical properties of highly weathered soils in the tropics with charcoal-A review. Biol. Fertil. Soils 2002, 35, 219-230. [CrossRef]

25. Steiner, C.; Teixxeira, W.G.; Lehmann, J.; Nehls, T.; de Macedo, J.L.V.; Blum, W.E.H.; Zech, W. Long-term effects of manure, charcoal and mineral fertilization on crop production and fertility on a highly weathered central Amazonian upland soil. Plant Soil 2007, 292, 275-290. [CrossRef]

26. Asai, H.; Samson, B.K.; Stephan, H.M.; Songyikhangsuthor, K.; Homma, K.; Kiyono, Y.; Inoue, Y.; Shiraiwa, T.; Horie, T. Biochar amendment techniques for upland rice production in Northern Laos 1 . Soil physical properties, leaf SPAD and grain yield. Field Crops Res. 2009, 111, 81-84. [CrossRef]

27. Hammes, K.; Schmidt, M.W.I. Changes of biochar in soil. In Biochar for Environmental Management: Science and Technology; Lehmann, J., Joseph, S., Eds.; Earthscan: London, UK, 2009; pp. 169-178.

28. Hossain, M.K.; Strezov, V.; Yin, C.K.; Nelson, P.F. Agronomic properties of wastewater sludge biochar and bioavailability of metals in production of cherry tomato (Lycopersicon esculentum). Chemosphere 2010, 78, 1167-1171. [CrossRef] [PubMed]

29. Laird, D.A.; Fleming, P.; Davis, D.D.; Horto, R.; Wang, B.; Karlen, D.L. Impact of biochar amendments on the quality of a typical Midwestern agricultural soil. Geoderma 2010, 158, 443-449. [CrossRef]

30. Elmer, W.H.; Pignatello, J.J. Effect of biochar amendments on mycorrhizal associations and fusarium crown and root rot of asparagus in replant soils. Plant Dis. 2011, 95, 960-966. [CrossRef] [PubMed]

31. Park, J.H.; Choppala, G.K.; Bolan, N.S.; Chung, J.W.; Chuasavathi, T. Biochar reduces the bioavailability and phytotoxicity of heavy metals. Plant Soil 2011, 348, 439-451. [CrossRef]

32. Kangoma, E.; Blango, M.M.; Rashid-Noah, A.B.; Sherman-Kamara, J.; Moiwo, J.P.; Kamara, A. Potential of biochar-amended soil to enhance crop productivity under deficit irrigation. Irrig. Drain. 2017. [CrossRef]

33. Schmidt, M.W.I.; Noack, A.G. Black carbon in soils and sediments: Analysis, distribution, implications and current challenges. Glob. Biogeochem. Cycles 2000, 14, 777-793. [CrossRef]

34. Schmidt, H.P. 55 Uses of Biochar. Ithaka J. 2012, 1, 286-289.

35. Conteh, A.M.H.; Yan, X.; Moiwo, J.P. The determinants of grain storage technology adoption in Sierra Leone. Cashier Agric. 2015, 24, 47-55. [CrossRef]

36. Wu, H.; Lai, C.; Zeng, G.; Liang, J.; Chen, J.; Xu, J.; Dai, J.; Li, X.; Liu, J.; Chen, J.; et al. The interactions of composting and biochar and their implications for soil amendment and pollution remediation: a review. Crit. Rev. Biotech. 2017, 37, 754-764. [CrossRef] [PubMed]

37. Nguyen, B.T.; Lehmann, J.; Hockaday, W.C.; Joseph, S.; Masiello, C.A. Temperature sensitivity of black carbon decomposition and oxidation. Environ. Sci. Technol. 2010, 44, 3324-3331. [CrossRef] [PubMed]

38. Filiberto, D.M.; Gaunt, J.L. Practicality of biochar additions to enhance soil and crop productivity. Agriculture 2013, 3, 715-725. [CrossRef]

39. Liu, X.; Zhang, A.; Ji, C.; Joseph, S.; Bian, R.; Li, L.; Pan, G.; Paz-Ferreiro, J. Biochar's effect on crop productivity and the dependence on experimental conditions-A meta-analysis of literature data. Plant Soil 2013. [CrossRef] 
40. Biederman, L.B.; Harpole, W.S. Biochar and its effects on plant productivity and nutrient cycling: A meta-analysis. GCB Bioenergy 2013, 5, 202-214. [CrossRef]

41. Peel, M.C.; Finlayson, B.L.; Mcmahon, T.A. Updated world map of the Köppen-Geiger climate classification. Hydrol. Earth Syst. Sci. Discuss. Eur. Geosci. Union 2007, 11, 1633-1644. [CrossRef]

42. Denis, M.K.A.; Kamara, A.; Momoh, E. Soil fertility status of three chiefdoms in Pujehun District of southern Sierra Leone. Res. J. Agric. Sci. 2013, 4, 461-464.

43. Weber, K.; Quicker, P. Properties of biochar. Fuel 2018, 217, 240-261. [CrossRef]

44. Dixon, W.J. Analysis of extreme values. Ann. Math. Stat. 1950, 21, 488-506. [CrossRef]

45. Karer, J.; Wimmer, B.; Zehetner, F.; Kloss, S.; Soja, G. Biochar application to temperate soils: Effects on nutrient uptake and crop yield under field conditions. Agric. Food Sci. 2013, 22, 390-403. [CrossRef]

46. Quintero, D.; Ancel, T.; Cassie, G.; Ceron, R.; Darwish, A.; Felix, G.G.; He, J.J.; Keshavamurthy, B.; Makineedi, S.; Nikalje, G.; et al. Workload Optimized Systems: Tuning POWER7 for Analytics; An IBM Redbooks Publication: Atlanta, GA, USA, 2012; p. 200.

47. Augustenborg, C.A.; Hepp, S.; Kammann, C.; Hagan, D.; Schmidt, O.; Muller, C. Biochar and earthworm eff ects on soil nitrous oxide and carbon dioxide emissions. J. Environ. Qual. 2012, 41, 1203-1209. [CrossRef]

48. Buss, W.; Kammann, C.; Koyro, H.-W. Biochar reduces copper toxicity in Chenopodium quinoa Wild. in a Sandy Soil. J. Environ. Qual. 2012, 1157-1165. Available online: www.crops.org.www.soils.org (accessed on 4 February 2019). [CrossRef] [PubMed]

49. Keuls, M. The use of the "studentized range" in connection with analysis of variance. Euphytica 1952, 1, 112-122. [CrossRef]

50. Africa Rice Center-WARDA); FAO; SAA. NERICA ${ }^{\circledR}$ : The New Rice for Africa-A Compendium; Somado, E.A., Guei, R.G., Keya, S.O., Eds.; Africa Rice Center (WARDA): Cotonou, Benin; FAO: Rome, Italy; Sasakawa Africa Association: Tokyo, Japan, 2008; p. 210.

51. Goyal, S.; Chander, K.; Mundra, M.C.; Kapooret, K.K. Influence of inorganic fertilizers and organic amendments on soil organic matter and soil microbial properties under tropical conditions. Biol. Fertil. Soils. 1999, 29, 196-200. [CrossRef]

52. Trujillo, L. Fluxos de Nutrientes em solo de Pastagem Abandonada sob Adubacao Organica e Mineral na Amazonia Central. Master's Thesis, INPA and University of Amazonas, Manaus, Brazil, 2002. 